\title{
O que vem se falando por aí em competências no ensino da promoção da saúde na formação do enfermeiro?
}

\author{
What has been talking on competence in health promotion \\ in nursing education?
}

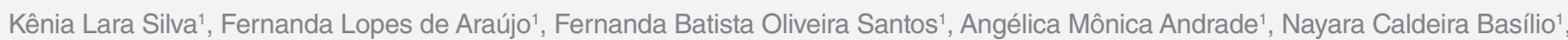
Roseni Rosângela de Sena

${ }^{1}$ Escola de Enfermagem da Universidade Federal de Minas Gerais (UFMG) - Belo Horizonte (MG), Brasil.

DOI: http://dx.doi.org/10.7322/abcshs.v40i3.809

\section{RESUMO}

O desenvolvimento de competências na formação dos profissionais de saúde tem sido discutido na literatura científica como forma de assegurar serviços de qualidade e foi tema recente de publicações importantes no cenário internacional. No entanto, o Brasil apresenta poucas experiências e produções sobre o tema. O estudo teve como objetivo analisar como são configuradas as competências para a promoção da saúde na formação do enfermeiro. Trata-se de revisão integrativa da literatura, na qual foram incluídos oito artigos, teses e dissertações publicados a partir do ano 2000 em inglês, espanhol e português. Os descritores utilizados para a busca foram: "promoção da saúde", "educação baseada em competências" e "competência profissional". A análise permitiu revelar as seguintes categorias temáticas: definição de competências, competências e promoção da saúde e ensino das competências em promoção da saúde. Os achados mostram que a maior parte da literatura é de origem internacional. A maioria guarda semelhança com as competências do CompHP e Consenso de Galway e apresentam a definição de competência como a combinação de três domínios: atitude, conhecimento e habilidades. A promoção da saúde é abordada em disciplinas como saúde pública, saúde da população e políticas de saúde. Evidencia-se que alunos vivenciam a experiência da promoção da saúde na comunidade. Ademais, a abordagem da promoção da saúde nos anos finais do curso é indicada como mais proveitosa que no início, pela maturidade (clínica e política) dos estudantes.

Palavras-chave: promoção da saúde; educação baseada em competências; educação em enfermagem.

\section{ABSTRACT}

The development of skills in the training of health professionals has been discussed in the scientific literature in order to ensure quality services and has recently been the subject of important publications in the international arena. However, in Brazil it has few experiences and productions about the theme. The study aimed to analyze how competencies for health promotion in nursing education are configured. This is an integrative literature review in which were included eight articles, theses and dissertations published since 2000 in English, Spanish and Portuguese. The descriptors used for the search were: "health promotion", "education based on skills" and "professional competence". The analysis unearthed the following thematic categories: definition of competencies, skills and health promotion and teaching of skills in health promotion. The findings show that most of the literature is of international origin. Most guard resemblance to the powers of CompHP and Galway Consensus and present the definition of competence as a combination of three areas: attitude, knowledge and skills. Health promotion is addressed in disciplines such as public health, population health and health policy. It is evident that students experience the health promotion practice in the community. Moreover, the approach to promoting health in the final years of the course is indicated as more profitable than at the beginning because of the maturity (clinical and policy) of the students.

Keywords: health promotion; competency-based education; education, nursing. 


\section{INTRODUÇÃO}

Competência é uma palavra do senso comum utilizada para designar uma pessoa qualificada para realizar alguma tarefa ${ }^{1}$. Tem sido objeto de estudo e discussão no campo da educação e do trabalho desde a década de 1970, época em que os psicólogos passaram a testar as competências das pessoas ao invés da inteligência ${ }^{2}$.

No campo específico da promoção da saúde, a denominação é "competências centrais", core competencies (em inglês), ou seja, um conjunto mínimo de competências essenciais que constitui um padrão para o desenvolvimento profissional dos sujeitos que estarão envolvidos na promoção da saúde ${ }^{2}$.

O termo promoção da saúde relaciona-se a um conjunto de valores: qualidade de vida, saúde, solidariedade, equidade, democracia, cidadania, desenvolvimento, participação e parceria. Para que haja promoção da saúde, diversos setores devem agir em comum, o Estado, por meio de políticas públicas, a comunidade, os indivíduos, o sistema de saúde. É, portanto, um conceito amplo que pressupõe a intersetorialidade ${ }^{3}$.

Cabe ressaltar que a utilização de competências para a promoção da saúde está pautada na potencialidade das competências valerem-se como ponto de referência para: estabelecer padrões profissionais, criar mecanismos que assegurem a qualidade de trabalho, selecionar profissionais para o trabalho, identificar e estruturar programas de treinamento e nortear a formação acadêmica ${ }^{2-5}$.

No que se refere ao cenário mundial, o tema competências em promoção da saúde tem sido discutido nos últimos anos em conferências internacionais para caracterizar e sistematizar os princípios fundamentais e de trabalho direcionados a essa área.

Um dos eventos que tratou desse assunto foi a Conferência de Galway, que definiu a Declaração do Consenso de Galway ${ }^{6}$. Esse documento aponta valores, princípios e domínios de competências centrais requeridas para o engajamento eficaz nas práticas de promoção da saúde, como catalisação de mudanças, liderança, estimativa/diagnóstico, planejamento, implementação, avaliação, advocacia e parcerias ${ }^{6}$.

Outro marco importante ocorreu em 2009, quando a União Internacional de Promoção e Educação para Saúde (UIPES), a partir do projeto "Desenvolvendo competências e padrões profissionais para a construção de capacidades e do fortalecimento institucional em promoção da saúde na Europa", criou o manual "Competências Principais em Promoção da Saúde - CompHP”2. Este acrescenta aos domínios de competências centrais definidos em Galway a comunicação, além dos conhecimentos básicos e valores éticos norteadores das competências centrais da promoção da saúde.

O desenvolvimento de competências na formação dos profissionais de saúde tem sido discutido na literatura científica como forma de assegurar serviços de qualidade e resolutivos e foi tema de publicações no cenário internacional ${ }^{2,6-8}$. No entanto, o Brasil apresenta poucas experiências e produções sobre a identificação e análise das competências para a promoção da saúde. Os estudos nacionais desenvolvidos até então têm se concentrado na aplicação do modelo de competências em programas específicos ${ }^{9}$.
Permanecem lacunas quanto às competências desenvolvidas nos processos formativos e quanto às estratégias de ensino que resultam em padrões profissionais adequados à transformação das práticas de atenção em favor da promoção da saúde.

O Núcleo de Estudos e Pesquisas sobre Ensino e Prática de Enfermagem (NUPEPE) desenvolve pesquisas relacionadas à educação em saúde e enfermagem e um dos seus eixos de trabalho é a educação em enfermagem. Um dos projetos realizados é o de "Competências para a promoção da saúde na formação do enfermeiro: experiências, resultados, desafios". A pesquisa é de amplitude nacional e conta com o financiamento das instituições: Fundação de Amparo à Pesquisa do Estado de Minas Gerais (FAPEMIG) e Conselho Nacional de Desenvolvimento Científico e Tecnológico (CNPq).

Buscando conhecer o universo de publicações indexadas acerca da temática das competências, o grupo de pesquisadores do NUPEPE realizou uma revisão integrativa com o objetivo de analisar, nas produções científicas da América Latina, da Europa e dos Estados Unidos da América, como são configuradas as competências para a promoção da saúde na formação do enfermeiro.

A relevância de empreender esta revisão centrou-se em colaborar com o projeto de competências do NUPEPE e conhecer e analisar o universo de publicações indexadas acerca da temática, $\mathrm{o}$ que por sua vez permitiu desvelar o que tem sido discutido acerca das competências para a promoção da saúde.

\section{MÉTODOS}

O método utilizado neste estudo foi o da revisão integrativa da literatura, pois permite reunir e sintetizar resultados de pesquisas sobre um delimitado tema ou questão, de maneira sistemática e ordenada, contribuindo para o aprofundamento do conhecimento do tema investigado ${ }^{10}$.

Para a realização da revisão integrativa, realizou-se um protocolo. Este previu a organização da revisão integrativa em seis etapas: escolha da pergunta da pesquisa; definição dos critérios de inclusão e seleção da amostra; representação dos estudos selecionados em formato de quadros temáticos, considerando todas as características em comum; análise dos achados; interpretação dos resultados e sua apresentação de forma clara ${ }^{11}$.

Definiu-se a seguinte questão norteadora: "Que competências para a promoção da saúde são trabalhadas na formação do enfermeiro?". Em seguida, delimitaram-se os seguintes critérios de inclusão: artigos, teses e dissertações que respondessem à pergunta da pesquisa e apresentassem resumo; fossem publicados a partir do ano 2000; estivessem em inglês, espanhol ou português. Os descritores selecionados foram: "promoção da saúde", "educação baseada em competências" e "competência profissional". Como estratégia de busca, utilizamos o recurso "and" entre os descritores, que deveriam estar contidos no resumo e/ou no título das publicações indexadas. A busca dos trabalhos foi realizada nas bases de dados Lilacs, Medline, Web of Science e Cinahl, 
as duas primeiras por meio dos portais da Biblioteca Virtual em Saúde (BVS) e do Pubmed, respectivamente, e as duas últimas pelo Portal de Periódicos da Capes. A busca pelos artigos compreendeu o período de março de 2014 a fevereiro de 2015.

As publicações encontradas para leitura dos resumos foram: dois na Lilacs, 17 na Medline, zero na Web of Science e zero na Cinahl, dos quais se seguiu para a leitura flutuante dos resumos a fim de verificar os que tinham como objeto a temática proposta. Dessa busca, foram excluídos nove artigos que não respondiam à pergunta de pesquisa e um artigo cujo texto não estava disponível inteiramente. Em seguida, os nove textos foram lidos na íntegra e foram excluídos dois que não respondiam à pergunta de pesquisa. A partir de um dos sete artigos selecionados, foi realizada a busca reversa de um trabalho que, por sua vez, foi somado à amostra final. Assim, oito manuscritos foram selecionados, numerados aleatoriamente e armazenados no banco de dados. A Figura 1 sintetiza o processo de busca dos artigos.

Seguiu-se com a análise temática (quadro temático). O quadro temático tinha como objetivo traçar um panorama geral dos artigos, salientando que competências são citadas por cada um desses autores, e os artigos foram distribuídos em dois quadros para melhor visualização. Para a composição dos quadros temáticos, foram extraídas informações de cada artigo: título, autores, periódico/ano/QUALIS/valor de impacto, tipo de estudo/metodologia, principais resultados, definição de competências, competências incluídas nos programas, observações do pesquisador e referência. A lista dos artigos que compuseram a amostra final, com seus respectivos autores e ano de publicação, é apresentada no Quadro 1.

\section{RESULTADOS E DISCUSSÃO}

$\mathrm{Na}$ descrição metodológica, entre as oito publicações analisadas, seis apresentam caráter descritivo ${ }^{12-14,16-18}$ e há um estudo randomizado ${ }^{15}$ e um estudo de reflexão ${ }^{19}$.

A análise dos artigos incluídos nesta revisão permitiu revelar as categorias temáticas "definição de competências", "competências e promoção da saúde" e "ensino das competências em promoção da saúde”, conforme o quadro síntese (Quadro 1).

\section{Definição de competências}

Competência é definida como "conjunto de conhecimentos, habilidades e atitudes"14,15,18. A literatura mostra que, além de

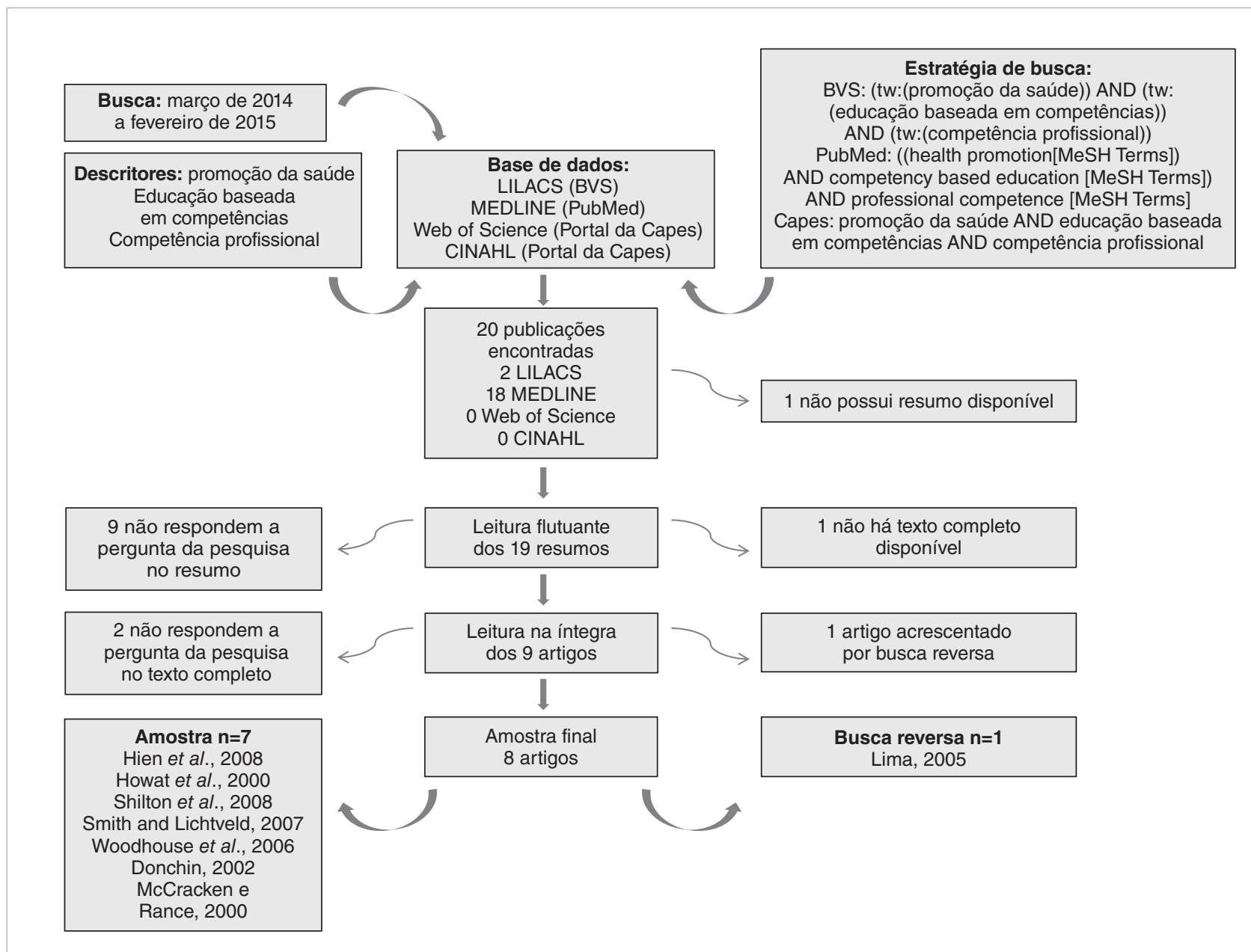

Figura 1: Processo de busca dos artigos 
Quadro 1: Caracterização dos artigos que compuseram a amostra final e sua divisão em categorias temáticas

\begin{tabular}{|c|c|c|c|c|c|c|}
\hline Referência & $\begin{array}{c}\text { Titulo da } \\
\text { publicação }\end{array}$ & Autor(es) & $\begin{array}{c}\text { Ano da } \\
\text { publicação }\end{array}$ & $\begin{array}{l}\text { Definição de } \\
\text { competências }\end{array}$ & $\begin{array}{l}\text { Competências } \\
\text { e promoção } \\
\text { da saúde }\end{array}$ & $\begin{array}{l}\text { Ensino das } \\
\text { competências em } \\
\text { promoção da saúde }\end{array}$ \\
\hline 12 & $\begin{array}{l}\text { A Competency-Based } \\
\text { Approach to Expanding } \\
\text { the Cancer Care } \\
\text { Workforce }\end{array}$ & $\begin{array}{l}\text { Alison P. } \\
\text { Smith e } \\
\text { Maureen Y. } \\
\text { Lichtveld }\end{array}$ & 2009 & $\begin{array}{l}\text { Competências } \\
\text { tornaram-se os } \\
\text { blocos de construção } \\
\text { básicos para o } \\
\text { desenvolvimento da } \\
\text { força de trabalho em } \\
\text { muitos contextos; } \\
\text { tarefas ou funções } \\
\text { que uma pessoa } \\
\text { deve ser capaz de } \\
\text { fazer ou realizar. }\end{array}$ & $\begin{array}{c}\text { Não trabalha } \\
\text { com este tema. }\end{array}$ & $\begin{array}{c}\text { Não trabalha } \\
\text { com este tema. }\end{array}$ \\
\hline 13 & $\begin{array}{l}\text { Survey of Accredited } \\
\text { Master of Public Health } \\
\text { (MPH) Programs With } \\
\text { Health Education } \\
\text { Concentrations: } \\
\text { a Resource for } \\
\text { Strengthening } \\
\text { the Public Health } \\
\text { Workforce }\end{array}$ & $\begin{array}{l}\text { Lynn D. } \\
\text { Woodhouse, } \\
\text { M. Elaine } \\
\text { Auld, William } \\
\text { C. Livingood } \\
\text { e Lori A. } \\
\text { Mulligan }\end{array}$ & 2006 & $\begin{array}{l}\text { O texto trabalha } \\
\text { com a competência } \\
\text { adaptável, que é } \\
\text { aquela que considera } \\
\text { contextos variados } \\
\text { de atuação do } \\
\text { profissional e que } \\
\text { prioriza o trabalho } \\
\text { transdisciplinar }\end{array}$ & $\begin{array}{l}\text { As escolas de PS } \\
\text { devem desenvolver } \\
\text { competências em } \\
\text { quatro áreas da } \\
\text { saúde pública: } \\
\text { epidemiologia, } \\
\text { bioestatística, } \\
\text { administração em } \\
\text { saúde e saúde do } \\
\text { meio ambiente. }\end{array}$ & $\begin{array}{c}\text { Áreas prioritárias } \\
\text { no desenvolvimento } \\
\text { de competências: } \\
\text { ética em saúde } \\
\text { pública, política e } \\
\text { direito, saúde global, } \\
\text { competência cultural, } \\
\text { comunicação, } \\
\text { pesquisa participativa } \\
\text { de base comunitária, } \\
\text { informática, genômica. }\end{array}$ \\
\hline 14 & $\begin{array}{l}\text { Development of } \\
\text { competency-based } \\
\text { University health } \\
\text { promotion courses }\end{array}$ & $\begin{array}{l}\text { Peter Howat, } \\
\text { Bruce } \\
\text { Maycock, } \\
\text { Linda } \\
\text { Jackson, } \\
\text { Tony Lower, } \\
\text { Donna Cross, } \\
\text { Jenny Collins } \\
\text { e Karin van } \\
\text { Asselt }\end{array}$ & 2000 & $\begin{array}{l}\text { "[...] uma combinação } \\
\text { de atributos que } \\
\text { permitem que um } \\
\text { indivíduo execute } \\
\text { conjunto de tarefas } \\
\text { para um padrão } \\
\text { adequado [...]". } \\
\text { Competências } \\
\text { são compostas } \\
\text { de atributos como } \\
\text { conhecimentos, } \\
\text { habilidades e atitudes, } \\
\text { e pode ser ampla } \\
\text { e complexa ou } \\
\text { específica e simples. }\end{array}$ & $\begin{array}{l}\text { Avaliação das } \\
\text { necessidades, } \\
\text { planejamento, } \\
\text { implementação, } \\
\text { comunicação, } \\
\text { conhecimento, } \\
\text { organização e } \\
\text { gestão, avaliação, } \\
\text { uso de tecnologia. }\end{array}$ & $\begin{array}{c}\text { A lista de } \\
\text { competências tem } \\
\text { sido usada como parte } \\
\text { do desenvolvimento } \\
\text { e revisão dos Cursos } \\
\text { Acadêmicos de } \\
\text { Promoção da Saúde } \\
\text { oferecidos na Curtin } \\
\text { University. Como } \\
\text { exemplo, o curso } \\
\text { de bacharelado } \\
\text { em ciência de três } \\
\text { anos, no primeiro } \\
\text { ano oferece duas } \\
\text { disciplinas introdutórias } \\
\text { de PS e no segundo e } \\
\text { no terceiro anos são } \\
\text { as disciplinas } \\
\text { específicas de PS. }\end{array}$ \\
\hline 15 & $\begin{array}{l}\text { Effectiveness of a } \\
\text { capacity-building } \\
\text { program for community } \\
\text { leaders in a healthy } \\
\text { living environment: } \\
\text { a randomized } \\
\text { community-based } \\
\text { intervention in rural } \\
\text { Vietnam }\end{array}$ & $\begin{array}{l}\text { Le Thi Thu } \\
\text { Hien, Takehito } \\
\text { Takano, } \\
\text { Kaoruko } \\
\text { Seino, } \\
\text { Mayumi } \\
\text { Ohnishi } \\
\text { e Keiko } \\
\text { Nakamura }\end{array}$ & 2008 & $\begin{array}{l}\text { As competências } \\
\text { podem ser definidas } \\
\text { como o conhecimento, } \\
\text { as competências, } \\
\text { as habilidades para } \\
\text { lidar com questões } \\
\text { de saúde pública } \\
\text { (Canadian Institute } \\
\text { of Public Health } \\
\text { Inspector) e para } \\
\text { resolver problemas } \\
\text { na comunidade, e } \\
\text { comunicar-se de forma } \\
\text { eficaz com as pessoas } \\
\text { da comunidade }\end{array}$ & $\begin{array}{l}\text { Identificar os passos } \\
\text { requeridos para um } \\
\text { ambiente de vida } \\
\text { saudável; entender } \\
\text { os princípios para } \\
\text { reduzir os potenciais } \\
\text { riscos de saúde; } \\
\text { prover gestão de } \\
\text { saúde pública } \\
\text { para promover um } \\
\text { ambiente saudável; } \\
\text { aplicar os princípios } \\
\text { de habilidades de } \\
\text { comunicação em } \\
\text { saúde. }\end{array}$ & $\begin{array}{l}\text { Não trabalha } \\
\text { com } \\
\text { este tema. }\end{array}$ \\
\hline 16 & $\begin{array}{l}\text { Potential uses of } \\
\text { health promotion } \\
\text { competencies }\end{array}$ & $\begin{array}{c}\text { Trevor Shilton, } \\
\text { Peter Howat, } \\
\text { Ray James, } \\
\text { Cheryl } \\
\text { Hutchins e } \\
\text { Linda Burke }\end{array}$ & 2008 & Não define. & $\begin{array}{l}\text { Utiliza como } \\
\text { referência os autores } \\
\text { Shilton e Howat } \\
\text { na definição de } \\
\text { competências e } \\
\text { promoção da saúde. }\end{array}$ & $\begin{array}{c}\text { Deve haver maiores } \\
\text { oportunidades de se } \\
\text { usar as competências } \\
\text { em PS principalmente } \\
\text { nos cursos de } \\
\text { graduação, pois têm } \\
\text { uma duração de três } \\
\text { ou quatro anos, em } \\
\text { comparação com os } \\
\text { de pós-graduação, de } \\
\text { duração de um ano. }\end{array}$ \\
\hline
\end{tabular}


Quadro 1: Continuação

\begin{tabular}{|c|c|c|c|c|c|c|}
\hline Referência & $\begin{array}{c}\text { Titulo da } \\
\text { publicação }\end{array}$ & Autor(es) & $\begin{array}{c}\text { Ano da } \\
\text { publicação }\end{array}$ & $\begin{array}{l}\text { Definição de } \\
\text { competências }\end{array}$ & $\begin{array}{l}\text { Competências } \\
\text { e promoção } \\
\text { da saúde }\end{array}$ & $\begin{array}{l}\text { Ensino das } \\
\text { competências em } \\
\text { promoção da saúde }\end{array}$ \\
\hline 17 & $\begin{array}{l}\text { Principles for planning } \\
\text { the teaching of Health } \\
\text { Promotion in an MPH } \\
\text { course }\end{array}$ & Milka Donchin & 2002 & $\begin{array}{l}\text { Combinação de três } \\
\text { domínios: atitude, } \\
\text { conhecimento e } \\
\text { habilidade. }\end{array}$ & $\begin{array}{c}\text { Aborda a evolução } \\
\text { dos conhecimentos } \\
\text { de promoção da } \\
\text { saúde segundo a } \\
\text { Carta de Ottawa e } \\
\text { a Declaração de } \\
\text { Jakarta. Apresenta } \\
\text { três estratégias de } \\
\text { promoção da saúde: } \\
\text { advocacia, habilitação } \\
\text { e mediação. }\end{array}$ & $\begin{array}{l}\text { Não trabalha } \\
\text { com este tema. }\end{array}$ \\
\hline 18 & $\begin{array}{c}\text { Developing } \\
\text { Competencies for } \\
\text { Health Promotion } \\
\text { Training in Aotearoa - } \\
\text { New Zealand }\end{array}$ & $\begin{array}{c}\text { H. McCracken } \\
\text { e H. Rance }\end{array}$ & 2000 & $\begin{array}{l}\text { A força de trabalho } \\
\text { sinalizou um forte } \\
\text { apoio para uma } \\
\text { definição abrangente } \\
\text { de competência que } \\
\text { incluía não só os } \\
\text { conhecimentos e } \\
\text { as habilidades que } \\
\text { compõem a nossa } \\
\text { prática, mas também } \\
\text { os valores e princípios } \\
\text { éticos que guiam e } \\
\text { sustentam a promoção } \\
\text { da saúde. }\end{array}$ & $\begin{array}{l}\text { O processo } \\
\text { consultivo identificou } \\
\text { três grandes áreas: } \\
\text { 1) conhecimento, } \\
\text { habilidade, } \\
\text { 2) guia ético, } \\
\text { 3) visão da ética na } \\
\text { prática da PS em } \\
\text { Aotearoa - New } \\
\text { Zealand. }\end{array}$ & $\begin{array}{l}\text { Não trabalha } \\
\text { com este tema. }\end{array}$ \\
\hline 19 & $\begin{array}{c}\text { Competência: } \\
\text { distintas abordagens } \\
\text { e implicações } \\
\text { na formação de } \\
\text { profissionais de saúde }\end{array}$ & $\begin{array}{l}\text { Valéria } \\
\text { Vernaschi } \\
\text { Lima }\end{array}$ & 2005 & $\begin{array}{l}\text { } \\
\\
\end{array}$ & $\begin{array}{l}\text { Não trabalha } \\
\text { com este tema. }\end{array}$ & $\begin{array}{l}\text { "A orientação dos } \\
\text { currículos por } \\
\text { competência, na } \\
\text { área da saúde, } \\
\text { implica a inserção } \\
\text { dos estudantes, } \\
\text { desde o início do } \\
\text { curso, em cenários } \\
\text { da prática profissional } \\
\text { com a realização } \\
\text { de atividades } \\
\text { educacionais } \\
\text { que promovam o } \\
\text { desenvolvimento } \\
\text { dos desempenhos } \\
\text { (capacidades em } \\
\text { ação), segundo } \\
\text { contexto e critérios." } \\
\text { "A organização } \\
\text { curricular passa } \\
\text { a focalizar o } \\
\text { desenvolvimento das } \\
\text { áreas de competência } \\
\text { com a integração } \\
\text { e exploração de } \\
\text { situações-problema } \\
\text { reais ou simulados da } \\
\text { prática profissional." } \\
\text { "Nas situações reais, } \\
\text { sob supervisão, a } \\
\text { responsabilização e o } \\
\text { vínculo desenvolvidos } \\
\text { pelos estudantes } \\
\text { com pacientes, } \\
\text { com as equipes } \\
\text { de saúde e com a } \\
\text { própria organização e } \\
\text { avaliação dos serviços } \\
\text { prestados também } \\
\text { são considerados } \\
\text { elementos } \\
\text { constitutivos da } \\
\text { competência." }\end{array}$ \\
\hline
\end{tabular}

PS: promoção da saúde. 
conhecimentos e habilidades, devem-se considerar também os valores e os princípios éticos ${ }^{19}$. Esse conceito também é utilizado por outros autores que, por sua vez, buscam o entendimento da promoção da saúde como um movimento social e como referência integradora e orientadora do desempenho profissional ${ }^{20,21}$. Competência refere-se ao desempenho, sendo a estrutura subjacente que consente a interlocução dos diversos conhecimentos e atitudes imperativos à efetivação da ação ${ }^{20}$.

O desenvolvimento de competências está relacionado ao trabalho do indivíduo ${ }^{12}$. Ressalta-se que a competência desenvolvida no trabalho também é abordada ao destacar que profissionais da saúde precisam de um corpo de conhecimentos e competências para um desempenho adequado de seus papéis ${ }^{21}$.

Entre os oito artigos analisados, há um que trabalha a ideia de "competência adaptável"13. Nesta, o profissional deve apresentar as competências independente do local de trabalho, o que sugere uma versatilidade do perfil do especialista para se adaptar ao lócus. Enfatiza, ainda, a transdisciplinaridade em seu conceito e considera os múltiplos contextos de atuação profissional. Apresenta-se a ideia do trabalho em grupo, a horizontalização e democratização do conhecimento e o empoderamento, sendo este um dos eixos centrais da promoção da saúde ${ }^{22}$. Outro prevê contextos específicos em relação à literatura educacional ${ }^{19}$.

\section{Competências e promoção da saúde}

A promoção da saúde é abordada tomando como referenciais a Carta de Ottawa e a Declaração de Jacarta ${ }^{17}$. A "Carta de Ottawa” foi produzida na Primeira Conferência Internacional sobre Promoção da Saúde, realizada em Ottawa, no Canadá, em novembro de 1986, sendo um marco teórico no campo da Promoção da Saúde. Os principais objetivos da Carta de Ottawa baseiam-se na preparação e na execução de políticas públicas saudáveis; na criação de ambientes favoráveis à saúde; no apoio à ação comunitária; no desenvolvimento de habilidades pessoais; e na reorientação do sistema de saúde ${ }^{23}$.

A partir da Conferência de Ottawa, outros eventos internacionais debateram as discussões teóricas, conceituais e políticas da Promoção da Saúde, tais como Adelaide (no ano de 1988), Sundsvall (no ano de 1991), Jacarta (no ano de 1997) e México (no ano de 2000), e outras duas de caráter sub-regional em Bogotá ${ }^{24}$. A Declaração de Jacarta foi documentada após a Quarta Conferência Internacional sobre Promoção da Saúde realizada em Jacarta, na República da Indonésia, em julho de 1997, e retrata um olhar para os determinantes em saúde e uma abordagem para enfrentar os desafios para a promoção da saúde no século $\mathrm{XXI}^{25}$.

Embora o CompHP não tenha sido citado como arcabouço de nenhum dos estudos analisados, pode-se verificar que alguns estudos usam alguns domínios previstos nele, como planejamento, implementação, comunicação, avaliação, advocacia, parceria e liderança ${ }^{14,17,18}$. Salienta-se que outros também citam esses domínios ${ }^{21,26}$. Entretanto, há a utilização dos termos “colaboração" e "posição pró-ativa" como sinônimos para os domínios "parceria" e "liderança", respectivamente ${ }^{26}$. Ademais, para definir as competências, há o apoio na Declaração do Consenso de Galway ${ }^{6}$.

\section{Ensino das competências em promoção da saúde}

O cenário de desenvolvimento de competências em promoção da saúde são os cursos de graduação ${ }^{14,16,19}$. A graduação é considerada um lócus privilegiado para a formação para a promoção da saúde baseada em competências ${ }^{27}$. Outros reforçam os cursos de pós-graduação como cenário de formação em promoção da saúde $e^{13,18}$.

Em relação ao momento em que são abordadas as competências nos cursos de graduação, um estudo afirma ter disciplinas em três anos do curso, sendo que no primeiro ano trata-se de uma disciplina introdutória de promoção à saúde e nos segundo e terceiro anos há disciplinas específicas de promoção à saúde ${ }^{14}$. Sugere-se que o ensino de promoção da saúde aconteça nos períodos mais finais do curso, pois consideram significativo concentrar a aprendizagem em um momento em que os alunos estão mais receptivos ${ }^{27}$. Os autores ressaltam que os estudantes nos últimos períodos parecem ter uma visão mais adequada do papel do enfermeiro na promoção da saúde, o que sugere que a maturidade e a experiência possam contribuir para o desenvolvimento das competências pelos alunos.

Em relação às estratégias de desenvolvimento das competências em promoção da saúde, cita-se o estágio e discorre-se sobre a importância de trabalhá-las nesse momento de prática supervisionada $^{19,27}$. A esse respeito, destaca-se que a abordagem da promoção da saúde na prática configura-se como um desafio para universidades com grande número de estudantes, do ponto de vista prático ${ }^{27}$.

Entre outras formas de abordagem no ensino de competências para promoção da saúde na formação do enfermeiro, essa temática é tratada no âmbito de aulas teóricas ${ }^{13}$. A promoção da saúde também é abordada como uma disciplina distinta dentro do currículo em algumas universidades ${ }^{27}$.

Ressalta-se que a inserção da promoção da saúde nos currículos de enfermagem é mínimo, sendo referida às atividades de educação em saúde. Nesse contexto, salienta-se que há confusão entre os termos "educação em saúde" e "promoção da saúde", os quais muitas vezes são utilizados erroneamente como sinônimos ${ }^{28}$.

Ademais, destaca-se que a inclusão da promoção da saúde como um tema no currículo de enfermagem não é suficiente para atender à necessidade atual de reorientação da atuação nos serviços de saúde. No entanto, a fim de buscar agir como promotores de saúde, estudantes de enfermagem precisam ter experiência e compreensão desse papel, que, para alguns, no momento, permanece somente abstrato ${ }^{27}$.

$\mathrm{Na}$ pós-graduação, as competências fazem parte das disciplinas Ética em Saúde Pública, Política e Direito, Saúde global, Competência cultural, Comunicação, Pesquisa participativa de base comunitária, Informática e Genômica ${ }^{13}$. 
Vale destacar que se sugere priorizar o trabalho com as competências nos cursos de graduação devido ao maior tempo de duração, quando comparado aos cursos de pós-graduação, e a abordagem da promoção da saúde nos anos finais do curso é indicada como mais proveitosa do que no início, pela maturidade (clínica e política) dos estudantes ${ }^{16}$.

\section{CONSIDERAÇÕES FINAIS}

Por se tratar de uma revisão de literatura, devem-se ponderar as limitações que os resultados encontrados guardam em si uma vez que, apesar de a reprodutibilidade do estudo estar garantida, há a circunscrição das estratégias adotadas bem como dos descritores definidos. Isso por si só abre um leque de oportunidades para o investimento em outros estudos que tratem do tema.
Sobre os achados, destaca-se que eles revelam que a maior parte da literatura que tem abordado o tema competências para a promoção da saúde é de origem internacional e que ainda são poucos os estudos que trabalham a temática no nível educacional e, mais especificamente, nos currículos de graduação em enfermagem.

Pode-se afirmar que os trabalhos analisados referenciam direta ou indiretamente as competências para a promoção da saúde definidas em consensos internacionais, em especial o Consenso de Galway e o CompHP, sendo que nenhum dos artigos da amostra em questão retratam um modelo de competências para a promoção da saúde no cenário brasileiro.

Cabe relevar, por fim, que os estudos mostram que não há um padrão de desenvolvimento de competências para a promoção da saúde, seja no momento do curso - primeiro ou último ano -, ou na estratégia utilizada - aulas teóricas ou práticas e no nível de ensino superior - tanto na graduação como na pós-graduação.

\section{REFERÊNCIAS}

1. Fleury MTL, Fleury A. Construindo o Conceito de Competência. Rev Adm Contemp. 2001;5(spe):183-96. http://dx.doi.org/10.1590/S1415-65552001000500010

2. Barry MM, Battel-Kirk B, Dempsey C. The CompHP core competencies Framework for health promotion in Europe. Health Educ Behav. 2012;39(6):648-62. http://dx.doi.org/10.1177/1090198112465620

3. Buss PM. Promoção da saúde e qualidade de vida. Ciênc Saúde Coletiva. 2000:5(1):163-77. http://dx.doi.org/10.1590/S1413-81232000000100014

4. Shilton T. Health promotion competencies: providing a road map for health promotion to assume a prominent role in global health. Glob Health Promot. 2009;16(2):42-6. http://dx.doi.org/10.1177/1757975909104103

5. Santa-María Morales A, Battel-Kirk B, Barry MM, Bosker L, Kasmel A, Griffiths J. Perspectives on health promotion competencies and accreditation in Europe. Glob Health Promot. 2009;16(2):21-31. http://dx.doi.org/10.1177/1757975909104101

6. Allegrante JP, Barry MM, Airhihenbuwa CO, Auld ME, Collins JL, Lamarre MC, et al. Domains of Core Competency, Standards and Quality for Building Global Capacity in Health Promotion: The Galway Consensus Conference Statement. Health Educ Behav. 2009;36(3):476-82.

http://dx.doi.org/10.1177/1090198109333950

7. Arroyo HV. La formación de recursos humanos y el desarrollo de competências para la capacitación em promoción de la salud em América Latina. Glob Health Promot. 2009;16(2):66-72. http://dx.doi.org/10.1177/1757975909104111

8. Battel-Kirk B, Barry MM, Taub A, Lysoby L. A review of the international literature on health promotion competencies: identifying frameworks and core competencies. Glob Health Promot. 2009;16(2):12-20.

http://dx.doi.org/1757975909104100v

9. Tusset D. Competências em promoção da saúde no programa Saúde na Escola no Distrito Federal. Dissertação (Mestrado) -
Faculdade de Educação Física, Universidade de Brasília. Brasília: 2012

10. Mendes KDS, Silveira RCCP, Galvão CM. Revisão integrativa: método de pesquisa para a incorporação de evidências na saúde e na enfermagem. Texto Contexto Enferm. 2008;17(4):758-64. http://dx.doi.org/10.1590/S0104-07072008000400018

11. Ganong LH. Integrative reviews of nursing research. Rev Nurs Health. 1987;10(1):1-11.

http://dx.doi.org/10.1002/nur.4770100103

12. Smith AP, Lichtveld MY, Miner KR, Tyus SL, Gase LN A competency-based approach to expanding the cancer care workforce. Medsurg Nurs. 2009;18(1):38-49.

13. Woodhouse LD, Auld ME, Livingood WC, Mulligan LA. Survey of accredited master of public health (MPH) programs with health education concentrations: a resource for strengthening the public health workforce. Health Promot Pract. 2006;7(2):258-65. http://dx.doi.org/10.1177/1524839905284574

14. Howat P, Maycock B, Jackson L, Lower T, Cross D, Collins J, et al Development of competency-based University health promotion courses. Promot Educ. 2000;7(1):33-8.

15. Hien LTT, Takano T, Seino K, Ohnishi M, Nakamura K. Effectiveness of a capacity-building program for community leaders in a healthy living environment: a randomized community-based intervention in rural Vietnam. Health Promot Int. 2008;23(4):354-64. http://dx.doi.org/10.1093/heapro/dan035

16. Shilton T, Howat P, James R, Hutchins C, Burke L. Potentia uses of health promotion competencies. Health Promot J Austr. 2008;19(3):184-8.

17. Donchin M. Principles for planning the teaching or Health Promotion in an MPH course. Public Health Rev. 2002;30(1):231-8.

18. McCracken H, Rance $H$. Developing competencies for health promotion training in Aotearoa - New Zealand. Promot Educ. 2000;7(1):40-3.

http://dx.doi.org/10.1177/102538230000700114 
19. Lima VV. Competência: distintas abordagens e implicações na formação de profissionais de saúde. Interface Comun Saúde Educ. 2005;9(17):369-79.

http://dx.doi.org/10.1590/S1414-32832005000200012

20. Egry EY, Marques CMS, Fonseca RMGS. A avaliação de competências na perspectiva crítico-emancipatória. Ciênc Cuidado Saúde. 2006;5(2):238-44.

http://dx.doi.org/10.4025/cienccuidsaude.v5i2.5087

21. Loureiro I. Competências para promover a saúde. Rev Port Pedagogia. 2009;43(2):81-103. http://dx.doi.org/10.14195/1647-8614_43-2_5

22. Chiesa MA, Nascimento GDD, Bracially DAL, Oliveira CAM, Coampone THM. A formação de profissionais da saúde: aprendizagem significativa à luz da promoção da saúde. Cogitare Enferm. 2007;12(2):236-40.

http://dx.doi.org/10.5380/ce.v12i2.9829

23. World Health Organization. The Ottawa Charter for Health Promotion. Ottawa, Canada: WHO; 1986.
24. Lima KMSV, Silva KL, Tesser CD. Práticas integrativas e complementares e relação com promoção da saúde: experiência de um serviço municipal de saúde. Interface Comun Saúde Educ. 2014;18(49);261-72.

http://dx.doi.org/10.1590/1807-57622013.0133

25. World Health Organization. Jakarta Declaration on Leading Health Promotion into the 21st Century. Jakarta: WHO; 1997.

26. Kemppainen $\mathrm{V}$, Tossavainen $\mathrm{K}$, Turunen $\mathrm{H}$. Nurses' roles in health promotion practice: an integrative review. Health Promot Int. 2012;28(4):490-501.

http://dx.doi.org/10.1093/heapro/das034

27. Mooney B, Timmins F, Byrne G, Corroon AMI. Nursing student's attitudes to health promotion to: implications for teaching practice. Nurse Educ Today. 2011;31(8):841-8. http://dx.doi.org/10.1016/j.nedt.2010.12.004

28. Whitehead D. Reviewing health promotion in nursing education. Nurse Educ Today. 2007;27(3):225-37. http://dx.doi.org/10.1016/j.nedt.2006.05.003 